\title{
The Social Impact of Cotton Planting in the Ming and Qing Dynasties
}

\author{
Rui $\mathrm{Hu}$ \\ College of History and Culture \\ Northwest Normal University \\ Lanzhou, China
}

\begin{abstract}
Since the introduction of cotton into China, the introduction and use of cotton has been recorded in various historical materials. Its introduction has had a great impact on the social life of ancient China, especially since the Ming Dynasty, the government has vigorously promoted cotton planting, making it being a must-have for life after food. Through analysis, this paper believes that the extensive cultivation of cotton in the Ming Dynasty changed the traditional planting structure based on agricultural mulberry, and promoted the development of handicrafts and commerce, which changed people's daily life.
\end{abstract}

Keywords-Ming and Qing dynasty; cotton; planting structure; handicraft; business development

\section{INTRODUCTION}

As an important material for apparel, the origin of cotton is not from China, but from the outside. As for the time and place of cotton introduction in China, the academic circles are still controversial. According to the relevant contents of "Shangshu-Yugong" and "Zhufanzhi", in the third century BC, women in southern China did not raise silkworms and planted other plants. Some scholars believe that this is the first time and place of cotton planting in China. In addition to the South China region, through the analysis of some literature and unearthed cultural relics, in the Han Dynasty, Xinjiang also introduced cotton through Tianzhu and other places. Before the Tang Dynasty, cotton was not well known to the Central Plains. In the Tang Dynasty, cotton fabrics were still tribute to other countries as tributes, indicating that cotton was still scarce at the time. Even a small range of plantings is seen as a "flower" in the garden, which was described in the 9th century by Arab traveler Suleiman in his "Suleiman Travels". Cotton began to grow in large areas in the Central Plains from the Song Dynasty. "In the Song and Yuan Dynasties, cotton began to spread in China. Guanzhong, Shaanxi, Fujian, and Guangdong first benefited from cotton planting." In the Yuan Dynasty, the relevant institutions were also set up in Jiangnan and other places to promote the cultivation of cotton. The two generations of the Song and Yuan Dynasties were still in the basic stage of cotton cultivation. Until the Ming Dynasty, cotton had a large-scale development. Although cotton was introduced into China earlier, it has been developing slowly for a long time. Before the Ming Dynasty, cotton cultivation was in the frontier of China, away from the economic and cultural center of the Central Plains, and it was not recognized as a raw material for clothing, therefore, the impact on the country is small. However, since the Ming Dynasty, with the widespread promotion and cultivation of cotton, the status of cotton has risen and gradually developed into daily necessities after food, and it has had a self-evident influence on the economy and society during the Ming and Qing Dynasties.

\section{Changed the Traditional Planting Structure}

Since ancient times, China has had an economic pattern dominated by "agricultural mulberry". This is the basis for the daily necessities of food and clothing. It has long occupied the primacy of the national economic structure. The food is mainly "grain" and the clothing is mainly mulberry. Therefore, the "grain mulberry" agricultural and mulberry structure has become the main traditional planting structure in the country for thousands of years. Before the Song and Yuan Dynasties, in addition to food crops, silk and hemp were the main materials for clothing in the long history. As necessities for life their cultivation and production have received special attention At the same time, under the influence of the policies of the rulers who encouraged the peasants of the past, the scope, density and production of silk and hemp were far superior to other cash crops. It has a dominant position in traditional agricultural planting structures. Under the influence of factors such as use and policy promotion, the ancient society gradually formed a traditional planting structure based on agricultural mulberry.

After the Song and Yuan Dynasties, cotton gradually began to be promoted and planted, especially in the Ming and Qing Dynasties, the government's efforts to promote cotton planting further increased. In the early days of the founding of the Ming Dynasty, Zhu Yuanzhang forced the cultivation of cotton throughout the country and adjusted it through taxation. He allowed cotton plants with more than $10 \mathrm{mu}$ of land. After the cotton harvest, cotton could be used instead of grain as a tax object. These are all recorded in the "History of the Ming Dynasty, Food and Good". The rulers' strong encouragement and advocacy, and the court's further decree on cotton planting, have made the cotton planting range gradually spread throughout the country. In the Ming Dynasty, Qiu Jun recorded the cotton planting situation at that time in "Daxue Yanyi $\mathrm{Bu}$ ": "In China, cotton was grown from north to south. Either the poor or the rich used cotton, its ability to produce silk is many times stronger than others." Moreover, according to the records of the Ming Dynasty, in the middle and late 
Ming Dynasty, the court collected cotton from two Zhili and eight administrative divisions including Shandong, Shanxi, Shanxi, Henan, Huguang, Jiangxi, Sichuan, and Zhejiang. Cotton was widely levied by the court, and the area extended from north to south. The scope involved almost the entire dynasty. The direction of the levy from the court also indicated the widespread cultivation of cotton at that time. Therefore, under the promotion of national policies, cotton has been widely planted and produced, and the amount of mulberry planted has decreased. Therefore, cotton has gradually broken the long-term monopoly position of mulberry as a raw material for clothing. Under the influence of cotton planting, the status of cotton is becoming more and more important, which gradually changes the traditional pattern of agricultural mulberry and forms a new planting pattern.

As a cash crop, cotton has a strong economic value and has a higher economic benefit than food. With the promulgation of the "one whip method" in the Ming Dynasty and the "distribution into the mu" tax policy in the Qing Dynasty, the traditional taxation policy based on population taxation was broken, which led to a surge in population. On the one hand, population growth caused tensions between people and land. On the other hand, the abolition of the head tax and the rapid population growth have made the population's dependence on the land loose during the Ming and Qing dynasties, and a large number of floating populations appeared. At this time, the role of cotton as a cash crop was highlighted. Among them, the contradiction between people and land requires economic crops to meet normal living needs and alleviate many problems caused by contradictions between people and land. The weakening of the dependency on land has led some people to switch to specialized handicraft production and commercial activities, which provided conditions for cotton from largescale planting to textile sales. In addition, the extensive cultivation of cotton, coupled with the introduction of a number of new cotton varieties, hybridization with local cotton varieties, cotton production has greatly improved. Due to the increase in production and the advantages as a cash crop, widespread planting has been caused by the advantage of profitability. With the southward shift of the economic center of gravity, a large number of people migrate southward, and the cotton planting area is more concentrated. At the same time, the Beijing-Hangzhou Grand Canal is open to navigation, and the cotton output is processed and transported to the whole country under convenient transportation. The demand for cotton fabrics has increased. This, in turn, drives the development of cotton cultivation. Under the two-way promotion of government guidance and social demand, cotton planting and production increased, and the number of crops such as hemp was reduced. The original traditional planting structure was gradually changed.

In the Ming and Qing Dynasties, the main use of cotton cultivation was to produce garments. Before the large-scale planting of cotton, the main materials used in the society were leather, silk, linen, etc. The most widely used ones were silk and burlap. Silk is made after silk spinning, but the whole process is complicated. Although the silk itself is light and soft, it is gorgeous and colorful, but the price is high, which is not commonly used by ordinary people. The price of hemp is low, and the comfort and wear resistance are barely satisfactory. Cotton has the dual advantages of both silk and hemp. It is not only price-friendly, but also very soft. Cotton is processed, made into cotton fabric, processed into garments, comfortable and soft, and the price is moderate. This double advantage, the people are very fond of cotton fabric, which will increase the social acceptance of cotton. According to the "Zhengding Fuzhi" in the Qianlong period, "the use of cotton can protect the cold, can produce oysters, cover the old and the young, and there is no bad." It can be seen that the advantages of cotton fabrics, such as practicality and comfort, have become a necessity for the lives of the public. No matter the age and class status, they all rely on the use of cotton fabrics. Not only that, but cotton is a treasure, and seeds can be used for daily life. Rods and leaves can be used as feed for animals. Roots can be used as medicine and have important medical value. The social utility and demand of cotton has also greatly stimulated the cultivation of cotton, and the widespread cultivation of cotton has also stimulated the changes in traditional planting structures.

\section{DRIVEN THE DEVELOPMENT OF RELATED HANDICRAFTS AND COMMERCE}

During the Song and Yuan Dynasties, the planting range of cotton was not extensive, but it was planted in some parts of the south, and there were few plants in the north. It was not until the Ming Dynasty that the planting range of cotton gradually expanded nationwide. At the beginning of the Ming Dynasty, although the court vigorously promoted the cultivation of cotton, the textile technology was still immature, and the popularity of cotton products was not high. Textile technology greatly limited the large-scale cultivation of cotton. With the expansion of cotton cultivation and the lack of demand for cotton fabrics, this requires improvements in textile technology. Under the stimulation of social needs, textile technology has been continuously improved and developed, thus forming the emergence of a new handicraft industry dominated by cotton textiles. The cotton planting industry has gradually developed into one of the important handicraft industries in the country. At the same time, the development of the cotton textile industry has further promoted the commercialization of cotton.

China has a long history of cotton development and utilization, but before the large-scale planting, the technology is not mature, far behind the production process of silk and other materials. $\mathrm{n}$ the Yuan Dynasty Tao Zongyi's "Nancun Zhui geng Lu", there are related records on cotton processing technology: "Because there is no relevant advanced technology, people can only rely on manual processing of cotton." It can be seen that the processing of cotton in the Yuan Dynasty is limited to the simplest tool application, while the processing of cotton is mainly carried out by hand. This is not only inefficient, but also the quality of the cotton fabric produced is not satisfactory. At the beginning of the Yuan Dynasty, the famous cotton textile artist Huang Daopo improved the textile technology of smashing, bombing, spinning and weaving from Hainan and other places, invented the car, improved the slingshot, and reformed the original spinning wheel to improve the efficiency of the textile. Not only that, but she also 
improved the final weaving, shortening the time of weaving and increasing the density and quality of the cloth. During the Ming and Qing Dynasties, the demand for cotton fabrics in the society was getting higher and higher, but the single color of cotton fabrics could not meet the needs of life. The demand of society led to the development of the cotton fabric printing and dyeing industry, and the scale gradually formed. The innovation of technology has greatly promoted the cultivation and promotion of cotton. During the Ming and Qing Dynasties, the court not only promoted the cotton planting, but also inherited the improvement of textile and weaving by Huang Daopo, and the printing and dyeing technology developed rapidly. Under the promotion of planting policies and the continuous innovation of textile technology, the continuous advancement of production to processing technology has also promoted the commercial development of the cotton industry.

The cotton textile industry in the Ming Dynasty mainly consisted of two major regions, north and south. Due to environmental and economic conditions, the development of the cotton handicraft industry in the south was better than the development of the northern cotton textile industry. It was once the cotton textile center at that time. The spinning technology in the north is poor, the quality of the cotton fabric spun is inferior, unbearable, and affected by economic conditions, textiles is mainly concentrated in the manual production of family-oriented households. With the widespread cultivation of cotton and the official promotion of textile technology, northern textile technology has also been developed. In Suning, Hebei, it is recorded like this "Looking at the advanced experience of the south, mimicking the air environment in the south, so that the quality of the fabrics weaved is the same as in the south". But despite this, the northern cotton weaving technology is still not as good as the south. The gap between the cotton fabrics in the north and the south has contributed to the circulation of cotton fabrics from south to north.

Since the Tang and Song Dynasties, the country's economic center of gravity has gradually moved southward. Until the Ming Dynasty, with the continuous development of the commodity economy, the dependence of farmers with land was relaxed. Many farmers lost their land and were completely separated from agriculture and began to engage in handicraft industry. At the same time, the cotton textile industry and the cotton printing and dyeing industry, which are derived from the large-scale cultivation of cotton, are growing in size. The development of the cotton handicraft industry requires a large number of manual laborers to engage in the processing of cotton. At this time, many farmers who lost their land are transferred to the processing of the cotton handicraft industry under the demand of society and the market. The finished cotton products enter the market with demand and enter the market through commercial forms. This requires some merchants to sell cotton fabrics. The production and sales of a large number of cotton fabrics form a complete commercial chain from planting, production to sales. At the same time, due to the lack of production technology in the north, the production of cotton fabrics is lower than the demand for cotton fabrics in the society. A large number of cotton fabrics in the south are transported to the north through commercial trade channels. The economy from cotton planting to textilemade cotton products has gradually emerged, which not only promotes the internal commercial development of the two regions, but also promotes the circulation of commodity trade between the North and the South. At the same time, it has greatly promoted the development of national business.

\section{CHANGES TO EVERYDAY LIFE}

Before cotton was planted in a large area, China's clothing was dominated by silk and linen, and China had a strict hierarchy on the materials used in clothing. Although each dynasty has different regulations, the only constant is that the silk satin is usually used by the upper layer and the nobility, and the ordinary people can only use the coarse fabric made of hemp. Because of the characteristics of the rough products such as linen, the hairy and rough clothes are not comfortable to wear, and the toughness is extremely poor, and it is easy to wear. Until the beginning of the Ming Dynasty, the material condition of the people still has no obvious change.

Although there were cotton fabrics in the Song and Yuan Dynasties, the output was low and the prices were high, and they could not be popularized. With the large-scale promotion and planting of cotton in the Ming Dynasty, the cotton textile industry has also prospered, and cotton has gradually spread. Song Yingxing also wrote in his "Exploitation of the Works of Nature" that "every place has people using cotton cloth." Due to the increased production of cotton, combined with the largescale cultivation and processing, the price is more affordable to ordinary people. Compared with linen, its softness and comfort, and its resistance to cold are more attractive to the public. The low price and comfortable characteristics make cotton fabrics widely used in the Ming and Qing Dynasties. The large-scale cultivation of cotton and the development of cotton have changed the development direction of apparel materials since the middle and late Ming Dynasty. In the ordinary people, the original materials used for hemp were gradually replaced by cotton. In the Qing Dynasty, there was almost no cotton clothing. Li Bing, a member of the Qing Dynasty, wrote in "Zhongmian Ji":"I used to go to Youzhou and Yanzhou to the north, Chu to Chu, Guangdong to the south, Jianghuai to the east, and Qin and $\mathrm{Yu}$ to the west. There was no place that cotton couldn't be grown." The "Zhengding Fuzhi" in the Qianlong period also has detailed records on the various roles of cotton. In short, the popularity of cotton cultivation and the development of the cotton industry have had a profound impact on the clothing from the Ming Dynasty to the modern times.

\section{CONCLUSION}

At the beginning of the introduction of cotton in China, it has not been promoted and popularized. However, with the change of the national agricultural mulberry policy, the transformation of the nation economic and trade forms, and the needs of people's lives, cotton has received more and more attention from the state. After the establishment of the Ming Dynasty, the traditional planting structure based on agriculture and mulberry was still continued. However, as a new type of cash crop, cotton has gradually been recognized by the rulers, and it has gradually begun to promote cotton planting 
nationwide. And through political means to encourage farmers to increase the amount of cotton planted, the traditional planting structure based on agriculture and mulberry has been changed. The promotion of the "One lash Method" policy of the Ming Dynasty eased the dependence of farmers on the land, which provided sufficient human support for the deep processing of cotton. At the same time, capitalism sprouted in the Ming Dynasty, and commodity trade prevailed in the whole society. Cotton fabrics have become an important product in the circulation of commodities. While promoting the development of merchandise trade, the growing demand for cotton fabrics has also stimulated the development of the cotton textile industry. In the folk life, the popularity of cotton fabrics has also changed the way people live. In short, the widespread promotion and cultivation of cotton, the development of cotton textile industry and the widespread use of cotton products have had a profound impact on the Ming and Qing Dynasties.

\section{REFERENCES}

[1] Xu Guangqi: Agricultural Administration book, Shanghai: Shanghai Classics Publishing House, 1985.

[2] Zhang Bingquan: "Ancient Cotton Fabrics in China", Taipei Institute of History and Language Research Institute, Taipei, 1981.

[3] Xu Dixin, Wu Chengming: "The Embryo of Chinese Capitalism", Beijing: People's Publishing House, 1985.

[4] Song Yingxing: "Exploitation of the Works of Nature ", Nanjing: Jiangsu Classics Publishing House, 2002.

[5] Zheng Dajin: "Zhengding Fuzhi", the twenty-seventh year of Qing Emperor Qianlong.

[6] Tao Zongyi: "Nancun Zhuigeng Lu", Beijing: Zhonghua Book Company, 1959.

[7] Qiu Jun: "Daxue Yanyi Bu”, Beijing: JINGWAH press, 1999.

[8] Zhang Tingyu: History of Ming, Beijing: Zhonghua Book Company, 1974 . 